OPEN ACCESS

Edited by:

Davide M. Dominoni,

University of Glasgow,

United Kingdom

Reviewed by:

Theresa M. Jones,

The University of Melbourne, Australia

Rajesh Singhal,

Indian Grassland and Fodder

Research Institute (ICAR), India

${ }^{*}$ Correspondence:

Brett M. Seymoure

brett.seymoure@gmail.com

tThese authors have contributed equally to this work and share first authorship

Specialty section:

This article was submitted to Urban Ecology

a section of the journa

Frontiers in Ecology and Evolution

Received: 29 June 2021

Accepted: 26 August 2021

Published: 20 September 2021

Citation:

Crump MC, Brown C,

Griffin-Nolan RJ, Angeloni L,

Lemoine NP and Seymoure BM

(2021) Effects of Low-Level Artificial Light at Night on Kentucky Bluegrass

and an Introduced Herbivore.

Front. Ecol. Evol. 9:732959.

doi: 10.3389/fevo.2021.732959

\section{Effects of Low-Level Artificial Light at Night on Kentucky Bluegrass and an Introduced Herbivore}

\author{
Morgan C. Crump ${ }^{1,2,3 t}$, Cassandra Brown ${ }^{1,2 t}$, Robert J. Griffin-Nolan ${ }^{2,4}$, Lisa Angeloni2, \\ Nathan P. Lemoine ${ }^{5,6}$ and Brett M. Seymoure ${ }^{1,2,7 *}$
}

\begin{abstract}
1 Department of Fish, Wildlife, and Conservation Biology, Colorado State University, Fort Collins, CO, United States, ${ }^{2}$ Department of Biology, Colorado State University, Fort Collins, CO, United States, ${ }^{3}$ Department of Recreation, Parks, and Tourism Management, State College, PA, United States, ${ }^{4}$ Department of Biology, Syracuse University, Syracuse, NY, United States, ${ }^{5}$ Department of Biological Science, Marquette University, Milwaukee, WI, United States, ${ }^{6}$ Department of Zoology, Milwaukee Public Museum, Milwaukee, WI, United States, ${ }^{7}$ Living Earth Collaborative, Washington University in St. Louis, St. Louis, MO, United States
\end{abstract}

Increasing evidence suggests that artificial light at night (ALAN) can negatively impact organisms. However, most studies examine the impacts of ALAN on a single species or under high levels of artificial light that are infrequent or unrealistic in urban environments. We currently have little information on how low levels of artificial light emanating from urban skyglow affect plants and their interactions with herbivores. We examined how short-term, low levels of ALAN affect grass and insects, including growth rate, photosynthesis, and stomatal conductance in grass, and foraging behavior and survival in crickets. We compared growth and leaf-level gas exchange of Kentucky Bluegrass (Poa pratensis) under low-levels of ALAN (0.3 lux) and starlight conditions (0.001 lux). Furthermore, each light treatment was divided into treatments with and without house crickets (Acheta domesticus). Without crickets present, bluegrass grown under ALAN for three weeks grew taller than plants grown under natural night light levels. In the fourth week when crickets were introduced, grass height decreased resulting in no measurable effects of light treatment. There were no measurable differences in grass physiology among treatments. Our results indicate that low levels of light resulting from skyglow affect plant growth initially. However, with herbivory, the effects of ALAN on grass may be inconsequential. Gaining an understanding of how ALAN affects plantinsect interactions is critical to predicting the ecological and evolutionary consequences of anthropogenic light pollution.

Keywords: photosynthesis, urban light, growth rate, crickets (Gryllidae), photobiology

\section{INTRODUCTION}

Artificial light at night (ALAN) is an anthropogenic pollutant that is increasing spatially by a rate of $2.2 \%$ per year (Kyba et al., 2017). Direct ALAN sources, such as streetlights, can lead to skyglow: the atmospheric scattered light that can propagate up to several hundred kilometers into the environment (Luginbuhl et al., 2009; Aubé, 2015). Skyglow results in light encroaching into natural areas where direct sources of light pollution are not present (Gaston et al., 2015; Garrett et al., 2020). 
The study of ALAN as an anthropogenic pollutant is a relatively young field (Longcore and Rich, 2004; Seymoure, 2018; Dominoni et al., 2020; Sanders et al., 2021), with most studies conducted at relatively high levels of nocturnal light pollution (e.g., 10-100 lux) (Gaston et al., 2013) but see Alaasam et al. (2018); Sanders and Gaston (2018). For reference, a full moon could create ambient light levels of 0.3 lux on its brightest nights (Biberman et al., 1966; Kyba et al., 2017). These high light levels are representative of organisms functioning under direct light pollution, such as directly beneath a streetlight, whereas most urban environments exist at lower light levels due to skyglow (e.g., 0.1-1.0 lux), which can impact environments several hundred kilometers away from a direct light source (Gaston et al., 2013; Dominoni et al., 2014; Seymoure et al., 2019a). Therefore, examining the impacts of light pollution at high intensities, although informative, is not representative of artificial light conditions in urban habitats at night. It remains an open question as to whether low levels of skyglow illumination (0.001-0.3 lux) affects communities to the same extent as direct illumination.

The intensity and spectral composition of light depends upon the phase of the moon, season, and weather, all of which create necessary cues for organisms (Kyba et al., 2015; Spitschan et al., 2016; Seymoure et al., 2019b). Plants use light as a cue for almost every physiological process including, but not limited to, seedling development, photosynthesis, growth, and budding (Briggs and Christie, 2002; Takemiya et al., 2005; Bennie et al., 2016; Gaston et al., 2017; Singhal et al., 2018). In addition to powering the electron transport chain in thylakoid membranes, light intensity and direction impacts photosynthetic efficiency through phototropism (i.e., the movement of the plant toward sunlight; (Celaya and Liscum, 2005), chloroplast movements (Wada et al., 2003), and light-induced stomatal opening to optimize water-use efficiency (Dietrich et al., 2001). Periods of darkness are also important for plant metabolic processes, particularly stress recovery, including recovery from herbivory events (McNaughton, 1983; Singhal et al., 2018).

Increased levels of ALAN from urbanization are changing natural light regimes by increasing the intensity and duration of light available at night (Davies et al., 2013; Seymoure et al., 2019a; Buxton et al., 2020), potentially altering plantherbivore interactions. For example, by masking natural night light levels, ALAN can mislead herbivores to be more active at night and disrupt plant-herbivore interactions and critical dark recovery periods for plants (Dominoni et al., 2020). Plants in light polluted environments may experience changes in pollination, photoreceptor signaling, phenology and flowering (Ffrench-Constant et al., 2016; Singhal et al., 2018), which can have ecological consequences for food web dynamics (Polis et al., 2004). However, little is known about how constant illumination at the level of urban light alters plant-insect interactions. ALAN has led to declines in population sizes of a diversity of insect species through its interference with insect development, movement, foraging, and reproductive success, which can alter trophic systems (Owens and Lewis, 2018; Owens et al., 2020).

Here we test whether short-term exposure to ALAN affects plant-insect interactions by modifying plant photobiology and growth rates. We exposed two common urban speciesKentucky bluegrass (Poa pratensis), a cool season common turfgrass (Weissman and Rentz, 1977; Read et al., 1999; Suplick-Ploense and Qian, 2005), and the house cricket (Acheta domesticus), a nocturnal herbivore - to starlight (0.001 lux) and realistic urban nighttime light levels (0.3 lux) (Dominoni et al., 2013; Alaasam et al., 2018; Seymoure et al., 2019a) in order to test the following hypotheses: (1) Low levels of ALAN affect plant physiology. We predicted that plants grown under urban light would have higher net photosynthesis and dark respiration, increased growth rates, and increased stomatal conductance compared to control plants grown under starlight conditions. (2) Herbivory interacts with ALAN to affect plant biomass. We predicted cricket herbivores would reduce the biomass and height of grass. However, as crickets are nocturnal foragers, we predicted they would consume less plant material under urban light than starlight conditions and have lower survival rates in urban light.

\section{MATERIALS AND METHODS}

\section{Light Treatments}

We used a CMP6050 growth chamber (BDR16, Version 4.06 , Conviron, Winnipeg, Manitoba) set to a temperature of $22.2^{\circ} \mathrm{C}$ with light control to create artificial light environments (0.3 lux, hereafter "urban light") and natural new moon light environments (0.001 lux, hereafter "starlight") at night (Dominoni et al., 2013; Alaasam et al., 2018; Seymoure et al., 2019a; Jones et al., 2020). Daytime light levels were 135, 300 lux, which is similar to natural daytime lux levels. There were two different light types in the chamber-high pressure sodium and mercury vapor-placed in alternating positions on the ceiling of the chamber. This is standard for the CMP6050 growth chamber. These lights were stepped up and down to simulate dawn and dusk in the chamber. Standard LED lights of the chamber remained off to create more realistic and desired light levels. To create urban light levels within the chamber, we used 4 layers of filter gels over the light sources (Rosco E-Colour \#211.9 Neutral Density Filter, Stamford, CT, United States) that attenuated 83\% of light. To further attenuate light, $90 \%$ black shade cloth was placed over starlight treatments, and $22 \%$ white shade cloth was placed over urban light environments. Shade cloth and filter gels only effect the quantity of light, but not the quality of light in the chamber. These were constructed as square boxes and placed over the plant treatment groups using PVC pipe and shade cloth. We confirmed that light levels were approximately 0.3 lux and 0.001 lux using a highly sensitive spectroradiometer (StellarNet Silver Nova, Tampa Bay, FL, United States) with a cosine corrected irradiance probe affixed to a 1000-micron optical fiber (StellarNet, Tampa Bay, FL, United States). We checked irradiance measurements using SpectraWhiz software (StellarNet, Tampa Bay, FL, United States); due to the low light levels, we set integration time to approximately $20 \mathrm{~s}$ for the 0.3 lux measurements and $8 \mathrm{~min}$ for the 0.001 lux measurements. This confirmed that light levels throughout the enclosure were within one order of magnitude of the chosen light level for each treatment: 0.3 and 0.001 lux. 


\section{Experimental Design}

On day 1 , Kentucky bluegrass seeds were sown in $10 \mathrm{~cm}$ round pots $(n=72)$ containing Scotts Miracle-Gro soil and placed in the growth chamber under experimental light conditions. On day 21, we measured the tallest blade of grass, then weeded down the pots randomly, excluding the tallest blade of grass, until there were 25 shoots of grass remaining. Weeding to a standard number of shoots ensured that there were no differences in grass abundance among measurements prior to the experiment (Lemoine et al., 2018). After the initial 21-day growth period, one randomly selected juvenile cricket, male or female, was placed in each of 36 designated cricket pots. Herbivory and light environments were examined using a $2 \times 2$ factorial design in which light treatment was factorially crossed with cricket treatment in a 28-day experiment. The four treatments were arranged in a block test pattern, as shown in Figure 1. Treatment groups included: (1) plants without crickets in urban light, (2) plants without crickets in starlight, (3) plants with crickets in urban light, and (4) plants with crickets in starlight ( $n=18$ per treatment). Nighttime lighting conditions were imposed in the middle of the day from the start of the experiment to ensure nighttime measurements could be taken during regular working hours. Lighting conditions were altered twice daily; we placed filter paper and shade cloth structures over the plants at 08:00 and removed them at 18:00 to create a 14:10 light:dark cycle typical of summer in the northern hemisphere. Blocks were rotated daily one position clockwise to account for spatial variation in light levels within the chamber, and generously watered at this time. Drierite (W.A. Hammond 23005, Xenia, OH, United States) was placed in two trays on opposite sides of the chamber to control humidity and prevent mold growth (Hammond, 1935).

Crickets were sourced as juveniles from a stock population from Premium Crickets (Winder, Georgia) in December 2018 as juveniles at a mean size of $1.9 \mathrm{~cm}$, before the adult phase. From day 21 to 28 , cricket survival was monitored daily (i.e., when light conditions were shifted) and categorized as alive or dead. All crickets were juveniles from day 21 to day 28 and thus we only report survival of juveniles. If a cricket was found dead, the cricket and its designated plant were removed from the experiment. Upon removal, we measured the height of the tallest blade of grass and recorded the length of time the plant/cricket spent in the chamber. We also cut and weighed aboveground biomass to determine wet and dry mass. On day 28 , we removed all remaining plants from the experiment and recorded the final height of the tallest blade of grass. We calculated the average daily growth rate in week four (day 21 to day 28) to control for plants that were removed prematurely due to cricket death.

\section{Gas Exchange Measurements}

To assess the effect of light treatment on bluegrass physiology independent of herbivory, we measured leaf photosynthetic responses on day 19 before crickets were placed into pots. We measured leaf gas exchange in each light treatment using a LI-6400XT infrared gas analyzer with a leaf chamber fluorometer attached (Li-Cor Biosciences; Lincoln, NE, United States) following previously published methods with slight modifications (Lemoine et al., 2018). Plants were removed from the growth chamber temporarily for gas exchange measurements. The environmental conditions inside the leaf chamber were standardized across measurements; leaf temperature was maintained at $20^{\circ} \mathrm{C}$, relative humidity was maintained between 40 and $50 \%$, sample chamber flow rate was set to $200 \mu \mathrm{mol}$ $\mathrm{m}^{2} \mathrm{~s}^{-1}$, and reference chamber $\mathrm{CO}_{2}$ concentration was set to $400 \mathrm{ppm}$. Low flow settings are commonly used for small leaved grasses with low photosynthetic rates (Taylor, 2014). Leaf level gas exchange was measured under two light conditions: dark and low light $\left(10 \mu \mathrm{mol} \mathrm{m} \mathrm{m}^{2} \mathrm{~s}^{-1}\right.$ (740 lux) photosynthetically active radiation; PAR). Gas exchange in the dark provides an estimation of leaf respiration. The low light level was the minimum amount of light provided by the Li-6400 light source;
Starlight

Urban Light

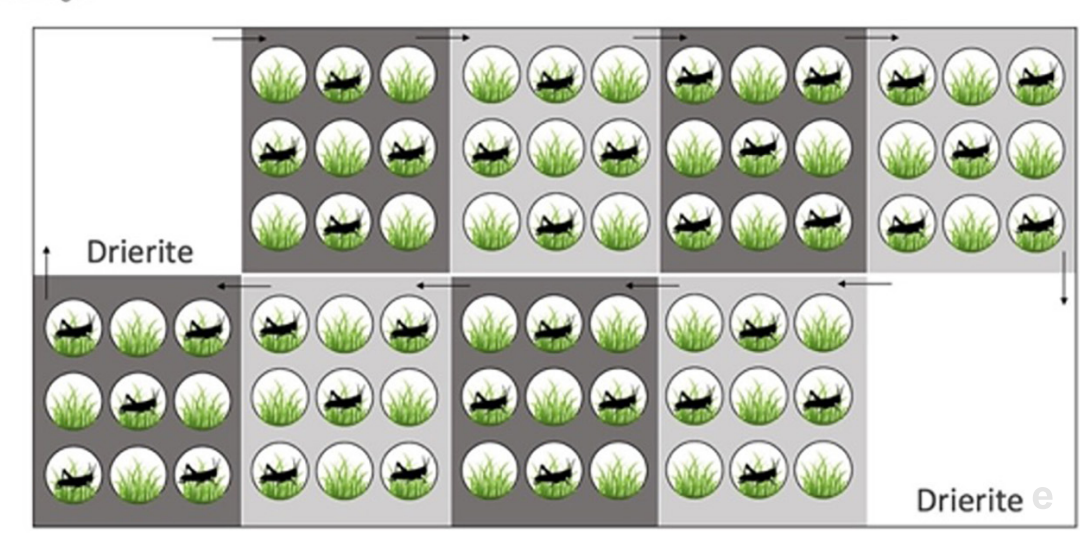

FIGURE 1 | Aerial view of treatment groups in the growth chamber after crickets were introduced (day 21-28). The treatment groups were arranged in a block test pattern with 4 blocks of urban light treatments and 4 blocks of starlight treatments, totaling 8 groups. Within each block, nine plants (every other one) had a cricket. 
thus, we were unable to measure photosynthesis under the tested ALAN conditions imposed here ( $<10$ umols, $<740$ lux), but instead measured whether treatments had an impact on plant photosynthetic responses to low levels of light. A newly emerged and fully expanded leaf from each individual $(n=10$ individuals per treatment) was inserted into the leaf chamber. Prior to measurements, leaves were dark adapted for $2 \mathrm{~h}$ under a dark box that allowed no light to enter. Leaves were left in the chamber for 2-5 min to equilibrate to chamber conditions before gas exchange parameters (photosynthesis or respiration, and stomatal conductance) were recorded (average of three logged values taken in rapid succession). Steady-state fluorescence (Fs) was measured continuously before exposing plants to a saturating pulse of light $\left(2,750 \mu \mathrm{mol} \mathrm{m} \mathrm{m}^{-2} \mathrm{~s}^{-1}\right.$ of blue light or $\sim 203,500$ lux) (Thimijan and Heins, 1983) to measure maximum chlorophyll fluorescence. Light inside the chamber was then

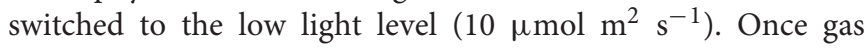
exchange reached stability, net photosynthetic rate and stomatal conductance were recorded, and a saturating pulse was applied to estimate photosystem II efficiency $(\Phi P S I I):$ PPSII $=\left(\mathrm{Fm}^{\prime}-\right.$ Fs)/Fm' where Fm' represents chlorophyll fluorescence under low light. As grass blades rarely filled the entire chamber, the measured leaf area was estimated using width and length, and photosynthetic parameters, which are based on the area of the chamber $\left(6 \mathrm{~cm}^{2}\right)$, were adjusted accordingly.

\section{Data Analysis}

All statistical analyses were performed in $\mathrm{R}$ version 3.4.3 (R Development Core Team, 1999). We first confirmed that our data were normally distributed to enable the use of parametric tests. To test our first hypothesis that gas exchange increased under ALAN, we ran a MANOVA with net photosynthetic rate, stomatal conductance, dark respiration, and ФPSII as response variables and with light treatment and block as explanatory variables (Figure 2). For our second hypothesis that light and cricket treatments would affect plant height, we modeled daily percent change in height between day 21 and day 28 using a two-way ANOVA with light treatment, cricket treatment, and block as explanatory variables (Figure 3 ). We then analyzed the data using two-way ANOVA, again with light treatment, cricket treatment, and block as explanatory variables, testing for an interaction between light treatment and cricket treatment. We also analyzed cricket survival using KaplanMeier analysis with the "survival" package in R (Figure 4) (Therneau and Lumley, 2009).

\section{RESULTS}

There was no difference in net photosynthesis, stomatal conductance, dark respiration, or $\Phi$ PSII between grass grown in the two light treatments (Table 1). On day 21, bluegrass grown in urban light was taller (mean $=5.35$, $\mathrm{sd}=1.02$ ) than bluegrass grown in starlight (mean $=4.79, \mathrm{sd}=0.63$, Table 2$)$. However, the daily percent change in plant height from day 21 to day 28 was not significantly different between treatments (Table 3 ). The presence of crickets did affect plant height, whereby bluegrass with crickets present were shorter than bluegrass without crickets (Table 3).

Crickets in the urban light treatment had a $25.0 \%$ probability of survival, whereas crickets in the starlight treatment had a survival probability of $32.1 \%$, but this difference was not statistically significant (Kaplan-Meier: $n=36, p=0.37$, Figure 4). There was no difference in survival due to sex (Kaplan-Meier: $n=36, p=0.80$, Figure 4).

\section{DISCUSSION}

Our study explored how short-term low levels of artificial light at night may affect immediate responses in plant photobiology and herbivore interactions. It is important to note that this study represents a brief novel environment akin to new lights being installed in an environment, and not long-term exposure. Contrary to our predictions, grass grown under low-level urban light conditions after 19 days did not have higher net photosynthetic rates than those grown under starlight, nor did stomatal conductance, dark respiration, or ФPSII differ significantly between light treatments. However, plants under urban light conditions grew taller than plants grown under starlight conditions during the initial 21 days of growth before crickets were introduced. Additionally, we found no evidence that crickets under urban light consumed more plant matter than crickets in starlight treatments, and survival rates of crickets did not differ between treatments. The results from this study suggest that short-term exposure to low levels of ALAN may not have significant effects on grass photobiology but may affect plant height.

Studies investigating grass responses to higher levels but similar durations of ALAN illumination (e.g., $4 \pm 1 \mu \mathrm{mol} \mathrm{m}^{-2}$ $s^{-1}$ or 296 lux) found that plant photoreceptors were sensitive to small fluxes in light levels, which can change flowering phenology (Thimijan and Heins, 1983; Shin et al., 2010; Bennie et al., 2016). Many flowering plants require dark photoperiod signals to induce flowering (Bennie et al., 2016) such that light pulses, even one minute long, are enough to change their phenology (Parker et al., 1952; Singhal et al., 2018). The lower levels of light tested here were likely not bright enough to induce these changes in bluegrass and may have allowed bluegrass to properly detect photoperiod. Furthermore, plants often use nighttime darkness to repair damage from UV rays, suggesting the low levels of ALAN in our treatments may be dark enough for plants to continue to repair damaged cells and photoreceptors (Singhal et al., 2018). Moreover, net photosynthesis is a dynamic measurement that can vary within samples due to time and day (Miller et al., 1996) and our single measurement at the end of week 3 may not have captured treatment differences occurring at other times.

We found no difference in stomatal conductance or respiration between plants grown in urban light and starlight. Other studies of similar 4-6 week duration did note differences in stomatal density and stomatal opening and closing in the presence of ALAN at levels from $0.1 \mu \mathrm{mol} \mathrm{m}{ }^{-2} \mathrm{~s}^{-1}$ to $1 \mu \mathrm{mol}$ $\mathrm{m}^{-2} \mathrm{~s}^{-1}$ of blue and red light (Takemiya et al., 2005; Shimazaki et al., 2007). Another study found that yellow-poplar trees 

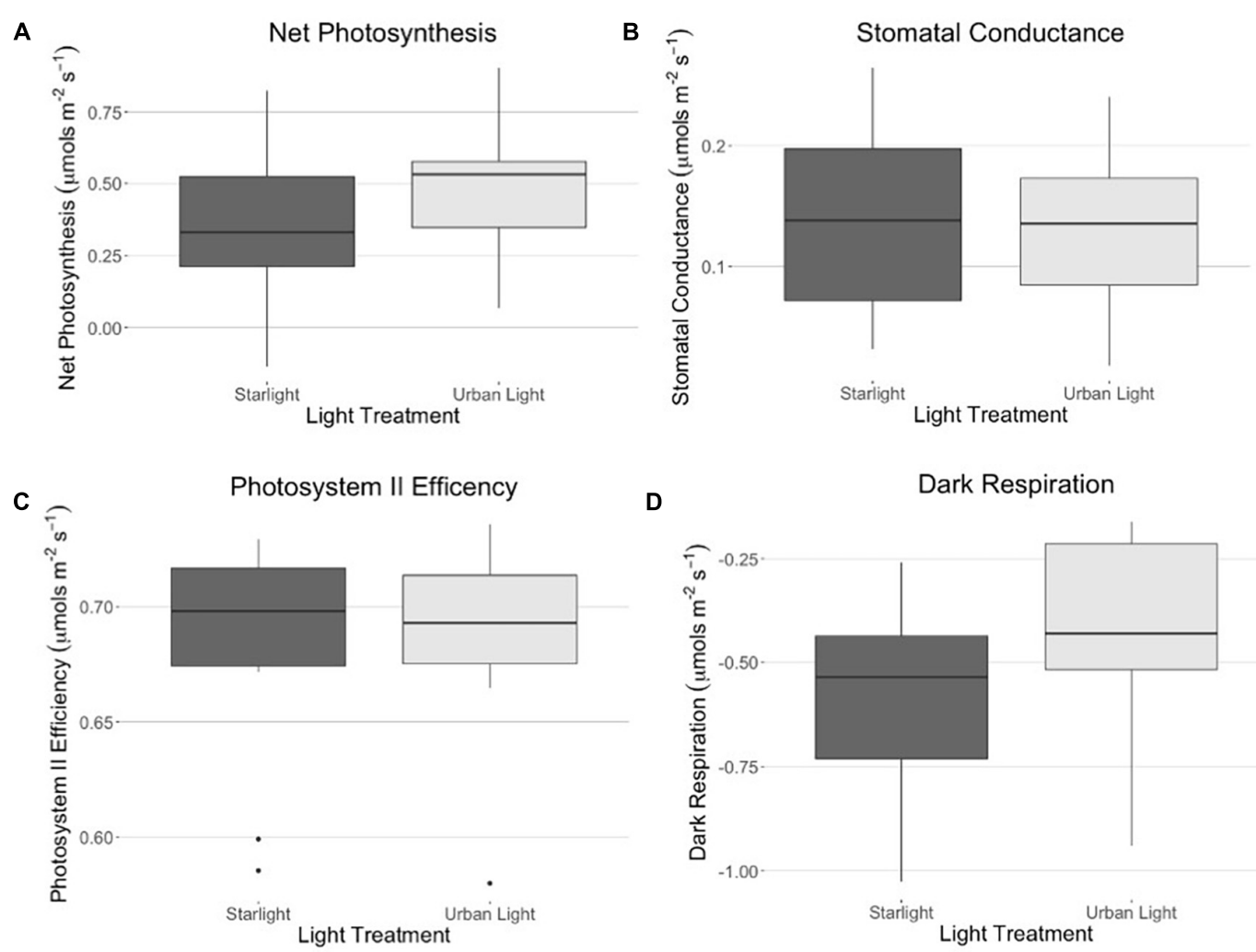

FIGURE 2 | (A) Net photosynthesis across light treatments, measured under low light conditions (10 $\mu$ mols $\mathrm{m}^{-2} \mathrm{~s}^{-1}$ of light) and (B) stomatal conductance across

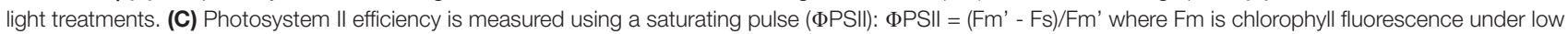
light. (D) Dark respiration measured in complete darkness. There were no differences in net photosynthesis, stomatal conductance, photosystem II efficiency, or dark respiration between light treatments.

\section{A}

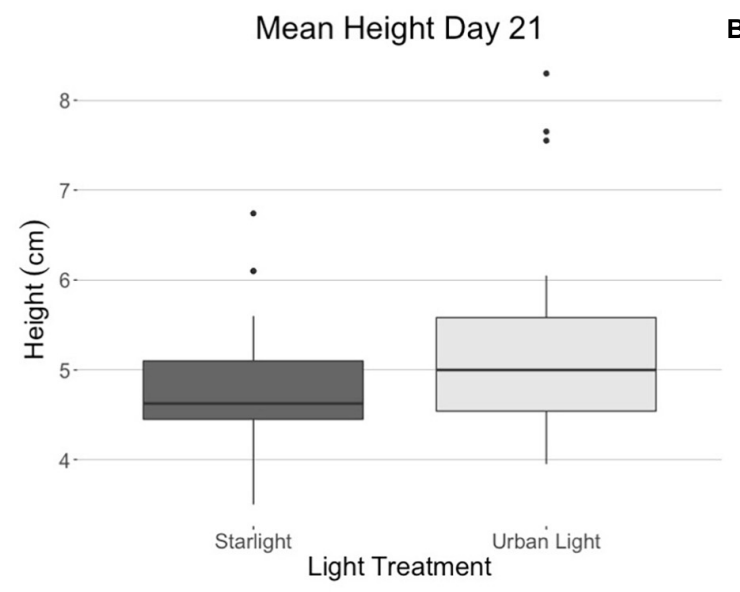

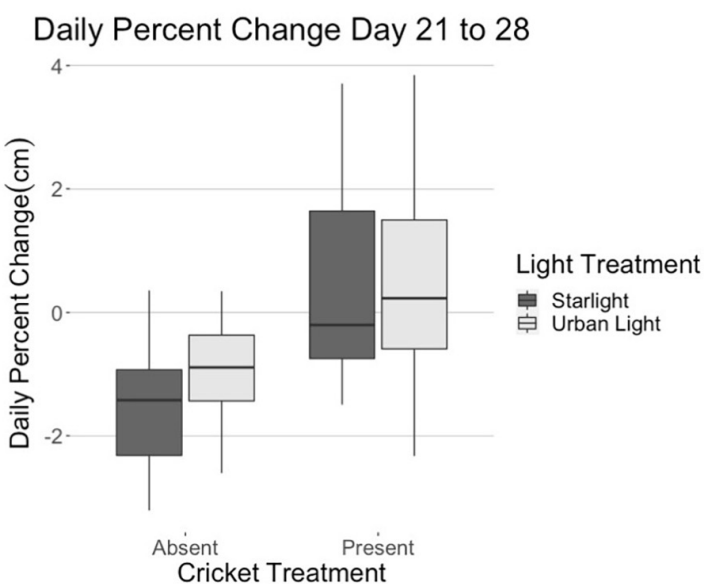

FIGURE 3 | (A) Bluegrass height at day 21 separated by light treatment when no crickets were present. Grass in urban light was taller than grass in starlight conditions. (B) Daily percent change in height of grass (change from day 21 to day 28 divided by the number of days in the chamber) separated by light treatment. There was no difference in daily percent change across light or cricket treatments.

exposed to ALAN (high pressure sodium lighting ranging from 82 lux to 4100 lux) for three years resulted in reduced nighttime stomatal conductance (Kwak et al., 2018). Given that we did not find any effects of ALAN on plant gas exchange, it is possible that our light levels were too low, or grass was not subjected to our light levels for a long enough duration, to induce such responses. Reduced chlorophyll and rubisco concentration has been observed in phytoplankton grown under low light levels (6.6 

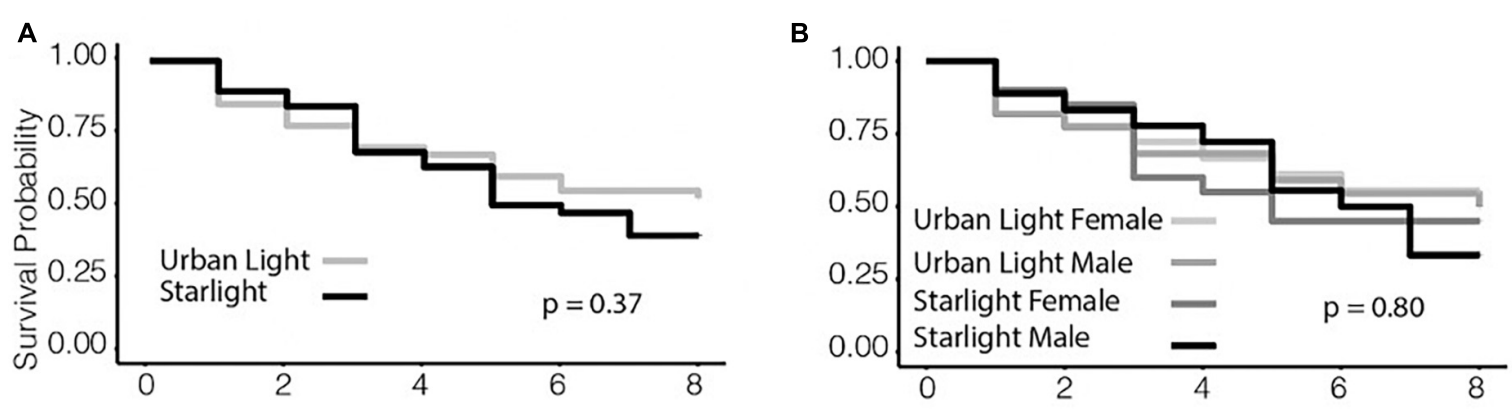

FIGURE 4 | Survival probability of crickets. (A) Survival probability of crickets under urban light and starlight treatments. (B) Survival probability of crickets under urban light and starlight treatments, split by sex in each treatment group. In both comparisons (A,B), there were no differences in survival.

lux; Poulin et al., 2014), and light as low as 3.5 lux has induced flowering in tree species across the United Kingdom (FfrenchConstant et al., 2016). We also observed no treatment effects on photosystem II efficiency despite other studies noting adverse reactions in these physiological responses to light pollution (Zhang and Reisner, 2019; Meravi and Prajapati, 2020). Kentucky Bluegrass might be more adaptable to changing light regimes given that it is commonly used as a turf grass selected for its resilience to drought and heat stress (Wang and Huang, 2004). We observed a faster growth rate for grasses grown under urban light conditions compared to starlight conditions before the introduction of an herbivore. Plant growth rate is determined by a variety of factors, including, but not limited to, photosynthetic rate, specific leaf area, leaf lifespan, leaf mass fraction, and nitrogen absorption rate (Campbell and Grime, 1989; Poorter et al., 1991; Osone et al., 2008). Although we found no difference in net photosynthetic rate between treatments, growth rate differences could have been due to greater allocation to leaf area in urban light (Poorter and Remkes, 1990) although we did not measure such attributes. Further, our ALAN levels of 0.3 lux, though extremely bright, still fall within the range of the natural lunar cycle, occurring during rare, very clear nights with full moons (Gaston et al., 2013); thus, bluegrass may have been well suited to handle the ALAN levels tested.

ALAN is known to alter photoperiod detection in multiple organisms (Bennie et al., 2016), and these changes in photoperiod can impact plant growth and flowering (Cathey and Campbell, 1975; Blanchard and Runkle, 2010; Basler and Körner, 2012; Craig and Runkle, 2016). Increased growth and biomass have been noted in Poaceae species when exposed to high levels of ALAN ranging from 0.349 to $1.145 \mu$ mols

TABLE 1 | MANOVA table of the gas exchange results evaluating differences in photosynthesis, stomatal conductance in dark, stomatal conductance in light, fluorescence, and photosystem II efficiency (Urban light, $n=11$; starlight, $n=11$ ).

\begin{tabular}{lcccc}
\hline & $\boldsymbol{d f}$ & Pillai & $\boldsymbol{f}$ & $\boldsymbol{p}$ \\
\hline Treatment & 1 & 0.18 & 0.45 & 0.83 \\
Block & 3 & 0.95 & 1.09 & 0.40 \\
Residuals & 17 & & &
\end{tabular}

$\mathrm{m}^{2} \mathrm{sec}^{-1}$ from metal halide bulbs (Flowers and Gibson, 2018), which corresponds to approximately 24.78-81.30 lux (Thimijan and Heins, 1983). However, after introduction of the herbivore, we observed no physiological responses in Kentucky Bluegrass, including no change in biomass. Photoperiod detection may not have been disrupted at our lower levels of ALAN, or it may have caused undetectable or non-measured physiological responses.

While animals rely on plants as a food source and shelter, we found no evidence that short term, low-level light pollution would impact these typical interactions between plants and insects. Artificial light at the level of 0.3 lux was not enough to induce changes in the amount of plant matter consumed by crickets or their survival, but light pollution at higher levels for longer periods of time could modify these interactions

TABLE 2 | ANOVA table comparing mean grass height at day 21 across light treatments and blocks.

\begin{tabular}{lccccc}
\hline & Sum of squares & $\boldsymbol{d f}$ & Mean square & $\mathbf{F}$ & $\boldsymbol{p}$ \\
\hline Light treatment & 3.50 & 1 & 3.50 & 5.63 & $0.021^{*}$ \\
Block & 7.87 & 6 & 1.31 & 2.11 & 0.064 \\
Residuals & 39.8 & 64 & 0.622 & & \\
\hline
\end{tabular}

*Indicates a significant response (Light treatment, urban light $n=36$, starlight $n=36)$.

TABLE 3 | ANOVA table showing the effects of light treatment, cricket treatment, and block (plus interactions between light and cricket treatment and cricket and block treatment) on daily percent change in grass height between day 21 and the end of the experiment.

\begin{tabular}{lccccc}
\hline & Sum of squares & $\boldsymbol{d} \boldsymbol{f}$ & Mean square & $\mathbf{F}$ & $\boldsymbol{p}$ \\
\hline Light treatment & 0.14 & 1 & 0.14 & 1.60 & 0.21 \\
Cricket treatment & 2.82 & 1 & 2.82 & 32.04 & $5.3 \times 10^{-7}$ \\
Block & 0.85 & 6 & 0.14 & 1.62 & 0.16 \\
Light: Cricket & 0.002 & 1 & 0.002 & 0.023 & 0.88 \\
Cricket: Block & 0.90 & 6 & 0.15 & 1.70 & 0.14 \\
Residuals & 4.93 & 56 & 0.088 & &
\end{tabular}

*Indicates a significant response (Light treatment, urban light $n=36$, starlight $n=36$; Cricket treatment, present $n=36$, absent, $n=36$ ). 
(Gaston et al., 2013; Macgregor et al., 2015; Bennie et al., 2016; Knop et al., 2017).

Overall, our research detected few changes to plant physiology under short-term exposure to low levels of urban light, suggesting that low levels of ALAN may not be as harmful to community interactions as predicted, at least initially. With rapid increase in human development, new lights are being introduced to unlit environments. Our experimental conditions may be representative of environments recently exposed to ALAN, such as a new housing development or newly urbanized areas. Other studies conducted at high levels of ALAN suggest artificial light can induce large changes in physiology and community interactions (Longcore and Rich, 2004; Gaston et al., 2013; Seymoure et al., 2019a). There may be a threshold level and length of exposure at which artificial light becomes harmful, causing detrimental effects to individual and ecosystem function with additional increases in intensity and duration. Understanding and identifying this threshold would allow for more effective management of night skies and natural light conditions (Dominoni et al., 2020). With estimates suggesting two thirds of Key Biodiversity Areas experience ALAN (Seymoure et al., 2019a; Garrett et al., 2020), it is important to identify the level at which artificial light becomes harmful and how natural night skies can be managed.

\section{DATA AVAILABILITY STATEMENT}

The raw data supporting the conclusions of this article will be made available by the authors, without undue reservation.

\section{REFERENCES}

Alaasam, V. J., Duncan, R., Casagrande, S., Davies, S., Sidher, A., Seymoure, B., et al. (2018). Light at night disrupts nocturnal rest and elevates glucocorticoids at cool color temperatures. J. Exp. Zool. Ecol. Integr. Physiol. 329, 465-472. doi: $10.1002 /$ jez.2168

Aubé, M. (2015). Physical behaviour of anthropogenic light propagation into the nocturnal environment. Philos. Trans. R. Soc. Lond. B Biol. Sci. 370:20140117. doi: $10.1098 /$ rstb.2014.0117

Basler, D., and Körner, C. (2012). Photoperiod sensitivity of bud burst in 14 temperate forest tree species. Agric. For. Meteorol. 165, 73-81. doi: 10.1016/j. agrformet.2012.06.001

Bennie, J., Davies, T. W., Cruse, D., and Gaston, K. J. (2016). Ecological effects of artificial light at night on wild plants. J. Ecol. 104, 611-620. doi: 10.1111/13652745.12551

Biberman, L. M., Dunkelman, L., Fickett, M. L., and Finke, R. G. (1966). Levels of Nocturnal Illumination. Alexandria: Institute for Defense Analyses.

Blanchard, M. G., and Runkle, E. S. (2010). Intermittent light from a rotating high-pressure sodium lamp promotes flowering of longday plants. HortScience 45, 236-241. doi: 10.21273/hortsci.45. 2.236

Briggs, W. R., and Christie, J. M. (2002). Phototropins 1 and 2: versatile plant blue-light receptors. Trends Plant Sci. 7, 204-210. doi: 10.1016/s1360-1385(02) 02245-8

Buxton, R. T., Seymoure, B. M., White, J., Angeloni, L. M., Crooks, K. R., Fristrup, K., et al. (2020). The relationship between anthropogenic light and noise in U.S. national parks. Landsc. Ecol. 35, 1371-1384. doi: 10.1007/s10980-020-01 020-w

\section{AUTHOR CONTRIBUTIONS}

$\mathrm{MC}, \mathrm{CB}, \mathrm{NL}$, and $\mathrm{BS}$ conceived and designed the experiment. $\mathrm{MC}, \mathrm{CB}, \mathrm{LA}$, and $\mathrm{BS}$ received funding for the study. $\mathrm{MC}$ and $\mathrm{CB}$ ran the study and collected data. $\mathrm{MC}, \mathrm{CB}$, and RG-N measured plant physiology. MC, CB, RG-N, NL, and BS analyzed the data. $\mathrm{MC}$ and $\mathrm{CB}$ wrote the manuscript with revisions from RG-N, LA, NL, and BS. All authors contributed to the article and approved the submitted version.

\section{FUNDING}

This work was supported through a Zoological Lighting Institute Grants-In-Aid of Research grant awarded to MC and CB. MC was awarded a SEEDS grant to present this research at the 2019 meeting of the Ecological Society of America (ESA) where we received excellent feedback from the ESA community. Furthermore, this work was supported through the Colorado State University Honors Program. NPS NSNSD contributed fundings to cover publication costs.

\section{ACKNOWLEDGMENTS}

We are grateful for support from the Smith Lab, the Sound and Light Ecology Team at Colorado State University, and the Natural Sounds and Night Skies Division of the National Park Service. Jeremy White, Tammy Brenner, and Bob Meadows were foundational to the success of this study.

Campbell, B. D. and Grime, J. P. (1989). A comparative study of plant responsiveness to the duration of episodes of mineral nutrient enrichment. New Phytologist 112, 261-267. doi: 10.1111/j.1469-8137.1989.tb02382.x

Cathey, H. M., and Campbell, L. E. (1975). Security lighting and its impact on the landscape. J. Arboricult. 1975, 181-187.

Celaya, R. B., and Liscum, E. (2005). Phototropins and associated signaling: providing the power of movement in higher plants. Photochem. Photobiol. 81, 73-80. doi: 10.1111/j.1751-1097.2005.tb01524.x

Craig, D. S., and Runkle, E. S. (2016). An intermediate phytochrome photoequilibria from night-interruption lighting optimally promotes flowering of several long-day plants. Environ. Exp. Bot. 121, 132-138. doi: 10.1016/j.envexpbot.2015.04.004

Davies, T. W., Bennie, J., Inger, R., and Gaston, K. J. (2013). Artificial light alters natural regimes of night-time sky brightness. Sci. Rep. 3:1722.

Dietrich, P., Sanders, D., and Hedrich, R. (2001). The role of ion channels in lightdependent stomatal opening. J. Exp. Bot. 52, 1959-1967. doi: 10.1093/jexbot/ 52.363.1959

Dominoni, D., Quetting, M., and Partecke, J. (2013). Artificial light at night advances avian reproductive physiology. Proc. Biol. Sci. 280:20123017. doi: 10.1098/rspb.2012.3017

Dominoni, D. M., Carmona-Wagner, E. O., Hofmann, M., Kranstauber, B., and Partecke, J. (2014). Individual-based measurements of light intensity provide new insights into the effects of artificial light at night on daily rhythms of urban-dwelling songbirds. J. Anim. Ecol. 83, 681-692. doi: 10.1111/1365-2656. 12150

Dominoni, D. M., Halfwerk, W., Baird, E., Buxton, R. T., Fernández-Juricic, E., Fristrup, K. M., et al. (2020). Why conservation biology can benefit from sensory ecology. Nat. Ecol. Evol. 4, 502-511. doi: 10.1038/s41559-020-1 $135-4$ 
Ffrench-Constant, R. H., Somers-Yeates, R., Bennie, J., Economou, T., Hodgson, D., Spalding, A., et al. (2016). Light pollution is associated with earlier tree budburst across the United Kingdom. Proc. Biol. Sci. 283:20160813. doi: 10. 1098/rspb.2016.0813

Flowers, N. D., and Gibson, D. J. (2018). Quantified effects of artificial versus natural nighttime lighting on the Eurasian grasses: Bothriochloa bladhii (Poaceae) and Bothriochloa ischaemum (Poaceae) and the North American grasses: Panicum virgatum (Poaceae) and Sorghastrum nutans (Poaceae). J. Torrey Bot. Soc. 145, 147-155. doi: 10.3159/torrey-d-17-00 038.1

Garrett, J. K., Donald, P. F., and Gaston, K. J. (2020). Skyglow extends into the world's Key biodiversity areas. Anim. Conserv. 23, 153-159. doi: 10.1111/acv. 12480

Gaston, K. J., Bennie, J., Davies, T. W., and Hopkins, J. (2013). The ecological impacts of nighttime light pollution: a mechanistic appraisal. Biol. Rev. Camb. Philos. Soc. 88, 912-927. doi: 10.1111/brv.12036

Gaston, K. J., Davies, T. W., Nedelec, S. L., and Holt, L. A. (2017). Impacts of artificial light at night on biological timings. Annu. Rev. Ecol. Evol. Syst. 48, 49-68. doi: 10.1146/annurev-ecolsys-110316-02 2745

Gaston, K. J., Duffy, J. P., and Bennie, J. (2015). Quantifying the erosion of natural darkness in the global protected area system. Conserv. Biol. 29, 1132-1141. doi: $10.1111 /$ cobi. 12462

Hammond, W. A. (1935). Use and regeneration of drierite. J. Chem. Educ. 12:445. doi: 10.1021/ed012p445

Jones, B. M., Seymoure, B. M., Comi, T. J., and Loew, E. R. (2020). Species and sex differences in eye morphometry and visual responsivity of two crepuscular sweat bee species (Megalopta spp., Hymenoptera: Halictidae). Biol. J. Linn. Soc. Lond. 130, 533-544. doi: 10.1093/biolinnean/bla a064

Knop, E., Zoller, L., Ryser, R., Gerpe, C., Hörler, M., and Fontaine, C. (2017). Artificial light at night as a new threat to pollination. Nature 548, 206-209. doi: $10.1038 /$ nature23288

Kwak, M. J., Je, S. M., Cheng, H. C., Seo, S. M., Park, J. H., Baek, S. G., et al. (2018). Night light-adaptation strategies for photosynthetic apparatus in yellow-poplar (Liriodendron tulipifera L.) exposed to artificial night lighting. For. Trees Livelihoods 9:74. doi: 10.3390/f902 0074

Kyba, C. C. M., Kuester, T., Sánchez de Miguel, A., Baugh, K., Jechow, A., Hölker, F., et al. (2017). Artificially lit surface of earth at night increasing in radiance and extent. Sci. Adv. 3:e1701528. doi: 10.1126/sciadv.170 1528

Kyba, C. C. M., Tong, K. P., Bennie, J., Birriel, I., Birriel, J. J., Cool, A., et al. (2015). Worldwide variations in artificial skyglow. Sci. Rep. 5:8409.

Lemoine, N. P., Griffin-Nolan, R. J., Lock, A. D., and Knapp, A. K. (2018). Drought timing, not previous drought exposure, determines sensitivity of two shortgrass species to water stress. Oecologia 188, 965-975. doi: 10.1007/s00442-018-4 265-5

Longcore, T., and Rich, C. (2004). Ecological light pollution. Front. Ecol. Environ. 2, 191-198.

Luginbuhl, C. B., Duriscoe, D. M., Moore, C. W., Richman, A., Wesley Lockwood, G., and Davis, D. R. (2009). From the ground Up II: sky glow and nearground artificial light propagation in Flagstaff, Arizona. PASP 121:204. doi: $10.1086 / 597626$

Macgregor, C. J., Pocock, M. J. O., Fox, R., and Evans, D. M. (2015). Pollination by nocturnal Lepidoptera, and the effects of light pollution: a review. Ecol. Entomol. 40, 187-198. doi: 10.1111/een.12174

McNaughton, S. J. (1983). Compensatory plant growth as a response to herbivory. Oikos 40, 329-336. doi: 10.2307/3544305

Meravi, N., and Prajapati, S. K. (2020). Effect street light pollution on the photosynthetic efficiency of different plants. Biol. Rhythm Res. 51, 67-75. doi: 10.1080/09291016.2018.1518206

Miller, D. P., Howell, G. S., and Flore, J. A. (1996). A whole-plant, open, gas-exchange system for measuring net photosynthesis of potted woody plants. HortScience 31, 944-946. doi: 10.21273/hortsci.31. 6.944

Osone, Y., Ishida, A., and Tateno, M. (2008). Correlation between relative growth rate and specific leaf area requires associations of specific leaf area with nitrogen absorption rate of roots. New Phytol. 179, 417-427. doi: 10.1111/j.1469-8137. 2008.02476.x

Owens, A. C. S., Cochard, P., Durrant, J., Farnworth, B., Perkin, E. K., and Seymoure, B. (2020). Light pollution is a driver of insect declines. Biol. Conserv. 241:108259. doi: 10.1016/j.biocon.2019.10 8259

Owens, A. C. S., and Lewis, S. M. (2018). The impact of artificial light at night on nocturnal insects: A review and synthesis. Ecol. Evol. 8, 11337-11358. doi: 10.1002/ece3.4557

Parker, M. V., Hendricks, S. B., Borthwick, H. A., and Jenner, C. E. (1952). Photoperiodic responses of plants and animals. Nature 169, 242-243. doi: 10. 1111/j.1469-8137.2008.02681.x

Polis, G. A., Power, M. E., and Huxel, G. R. (2004). Food Webs at the Landscape Level. Chicago: University of Chicago Press.

Poorter, H., and Remkes, C. (1990). Leaf area ratio and net assimilation rate of 24 wild species differing in relative growth rate. Oecologia 83, 553-559. doi: 10.1007/bf00317209

Poorter, H., van der Werf, A., Atkin, O. K., and Lambers, H. (1991). Respiratory energy requirements of roots vary with the potential growth rate of a plant species. Physiol. Plantarum 83, 469-475. doi: 10.1034/j.1399-3054.1991.830 321.x

Poulin, C., Bruyant, F., and Laprise, M. H. (2014). The impact of light pollution on diel changes in the photophysiology of Microcystis aeruginosa. J. Plankton Res. 36, 286-291. doi: 10.1093/plankt/fbt088

R Development Core Team. (1999). The R Reference Manual: Base Package. Network Theory. Boston, MA.

Read, J. C., Reinert, J. A., Colbaugh, P. F., and Knoop, W. E. (1999). Registration of "Reveille" hybrid bluegrass. Crop Sci. 39:590. doi: 10.2135/cropsci1999. 0011183x003900020059x

Sanders, D., Frago, E., Kehoe, R., Patterson, C., and Gaston, K. J. (2021). A metaanalysis of biological impacts of artificial light at night. Nat. Ecol. Evol. 5, 74-81. doi: 10.1038/s41559-020-01322-x

Sanders, D., and Gaston, K. J. (2018). How ecological communities respond to artificial light at night. J. Exp. Zool. Ecol. Integr. Physiol. 329, 394-400. doi: 10.1002/jez.2157

Seymoure, B. M, Buxton, R., White, J., Linares, C., Fristrup, K., Crooks, K., et al. (2019a). Anthropogenic light disrupts natural light cycles in critical conservation areas. [preprint]. doi: 10.2139/ssrn. 3439670

Seymoure, B. M., Linares, C., and White, J. (2019b). Connecting spectral radiometry of anthropogenic light sources to the visual ecology of organisms. J. Zool. 308, 93-110. doi: 10.1111/jzo.1 2656

Seymoure, B. M. (2018). Enlightening butterfly conservation efforts: The importance of natural lighting for butterfly behavioral ecology and conservation. Insects 9:22. doi: 10.3390/insects901 0022

Shimazaki, K.-I., Doi, M., Assmann, S. M., and Kinoshita, T. (2007). Light regulation of stomatal movement. Annu. Rev. Plant Biol. 58, 219-247. doi: 10.1146/annurev.arplant.57.032905.10 5434

Shin, J. H., Jung, H. H., and Kim, K. S. (2010). Night interruption using Light Emitting Diodes (LEDs) promotes flowering of Cyclamen persicum in winter cultivation. Horticult. Environ. Biotechnol. 51, 391-395.

Singhal, R. K., Kumar, M., and Bose, B. (2018). Ecophysiological responses of artificial night light pollution in plants. Russ. J. Plant Physiol. 66, 190-202. doi: 10.1134/s1021443719020134

Spitschan, M., Aguirre, G. K., Brainard, D. H., and Sweeney, A. M. (2016). Variation of outdoor illumination as a function of solar elevation and light pollution. Sci. Rep. 6:26756.

Suplick-Ploense, M. R., and Qian, Y. (2005). Evapotranspiration, rooting characteristics, and dehydration avoidance: Comparisons between hybrid bluegrass and Kentucky bluegrass. Int. Turfgrass Soc. Res. J. 10, 891-898.

Takemiya, A., Inoue, S.-I., Doi, M., Kinoshita, T., and Shimazaki, K.-I. (2005). Phototropins promote plant growth in response to blue light in low light environments. Plant Cell 17, 1120-1127. doi: 10.1105/tpc.104.03 0049 
Taylor, J. R. (2014). A simple inquiry-based lab for teaching osmosis. Am. Biol. Teach. 76, 265-269. doi: 10.1525/abt.2014.76.4.9

Therneau, T., and Lumley, T. (2009). Survival: Survival Analysis, Including Penalised Likelihood. R Package Version 2. Vienna: R Foundation for Statistical Computing.

Thimijan, R. W., and Heins, R. D. (1983). Photometric, radiometric, and quantum light units of measure: a review of procedures for interconversion. HortScience $18,818-822$.

Wada, M., Kagawa, T., and Sato, Y. (2003). Chloroplast movement. Annu. Rev. Plant Biol. 54, 455-468.

Wang, Z., and Huang, B. (2004). Physiological recovery of Kentucky bluegrass from simultaneous drought and heat stress. Crop Sci. 44, 1729-1736. doi: 10.2135/cropsci2004.1729

Weissman, D. B., and Rentz, D. C. F. (1977). Feral house crickets Acheta domesticus (L.)(Orthoptera: Gryllidae) in southern Calif. Entomol. News 88, 246-248.

Zhang, J. Z., and Reisner, E. (2019). Advancing photosystem II photoelectrochemistry for semi-artificial photosynthesis. Nat. Rev. Chem. 4, 6-21. doi: 10.1038/s41570-019-0149-4
Conflict of Interest: The authors declare that the research was conducted in the absence of any commercial or financial relationships that could be construed as a potential conflict of interest.

Publisher's Note: All claims expressed in this article are solely those of the authors and do not necessarily represent those of their affiliated organizations, or those of the publisher, the editors and the reviewers. Any product that may be evaluated in this article, or claim that may be made by its manufacturer, is not guaranteed or endorsed by the publisher.

Copyright (C) 2021 Crump, Brown, Griffin-Nolan, Angeloni, Lemoine and Seymoure. This is an open-access article distributed under the terms of the Creative Commons Attribution License (CC BY). The use, distribution or reproduction in other forums is permitted, provided the original author(s) and the copyright owner(s) are credited and that the original publication in this journal is cited, in accordance with accepted academic practice. No use, distribution or reproduction is permitted which does not comply with these terms. 